\title{
nature
}

\section{Half-way report on Chernobyl}

The Soviet Union has published this week only the least interesting parts of its report on the Chernobyl disaster. More needs to be said.

HUMAN crror is always a convenient explanation for catastrephe. It has the advantage, for the managers of great enterprises. that a few heads can be made to roll with some publicity without interfering too directly with the underlying programme. This is the spirit in which the surviving managers of the Soviet Union's still ambitious nuclear programme will no doubt be relieved by the publication earlier this week of an abridged version of the report on the Chernobyl disaster drawn up by the official investigating committee (see page 295). None of this implies that the explanation is incorrect. There is no reason to disbelieve the Soviet statement that the managers of the plant at Chernobyl behaved foolishly and "irresponsibly", or that they deserve to lose their jobs. Indeed, most Soviet statements about Chernobyl have been shown to have been accurate.

Nevertheless, the public interest in the Chernobyl disaster stems from the general concern that the world at large should have such a good understanding of how the accident happened that it is possible to make rational decisions about the future use of nuclear power as a source of electricity. Some, no doubt, seek further information so as to berate the hapless managers of nuclear industries elsewhere. Others seek the same information in the hope that it will demonstrate that nuclear power stations can be safely operated. The curiosity of both groups is legitimate, and must be satisfied. So must be that of the people most directly affected, the population of the region stretching for 400 square kilometres around the plant. The need now is for such a full disclosure of the circumstances leading to the accident that people will be able to judge for themselves whether the Chernobyl managers were as feckless as they are now said to be.

On present evidence, there is a long way to go before the circumstances are plain. It is said that those responsible at Chernobyl had been engaged in "experiments" not authorized by the licensing authorities when the accident happened, but there is no way of telling whether this was idle technological curiosity (unlikely on the eve of the May holiday) or, instead, a desperate attempt by unorthodox means to bring a wayward reactor under control. Similarly, there is not yet a sufficient explanation of the course of the accident itself. Monitoring stations elsewhere now clearly suggest that there was a second release of radioactive material from the reactor on the second day, presumably as a consequence of a further increase of the internal temperature. but the explanation remains for the time being hidden. Yet until this information is available, people outside the Soviet Union will remain on tenterhooks. There is again no reason to fear that the Soviet Union will not keep its promise to tell all. But this once secretive government now experimenting with openness clearly still has a lot to learn.

The Soviet managers of the nuclear industry need also to learn a little more caution about reactors of the type that went wrong at Chernobyl. One of the defects of this type of reactor is that the system becomes more reactive when water is lost from the cooling system, either because it leaks away or because it turns into steam. The consequence is an uncomfortable degree of instability which can also be a source of danger when something else goes wrong. But Soviet reactors of this type also lack the large pressure-tight containment vessels that would be required of them in the United States and most other places. It must now be a matter of grave concern whether the other reactors of this type, of which are more than twenty still in operation in the Soviet Union, can be safely allowed to continue.

In one respect, the Soviet government has responded constructively to the delivery of the report by setting up a new ministry with responsibility for the design and construction of new reactors. Obviously the intention is that the Soviet nuclear industry should in future be run on lines more appropriate for a military organization (which, in the circumstances, may be the best solution, although one conflicting with Mr Gorbachev's belief that there are too many ministries as there are). But the Soviet authorities should also pay some attention to the possibility that there may be other, better, solutions. Notoriously. Soviet industry is perennially crippled by the bureaucratic environment in which it must function. Part (but only part) of the trouble is that managers are responsible both to the government agency or ministry which has built their plant and to the Communist Party, working through its local and regional committees. This is a recipe for the division and even dilution of responsibility. At Chernobyl, it seems to have a been a recipe for disaster as well. Nobody would expect that a single nuclear accident would persuade the Soviet Union to forsake the path Lenin mapped out, but there is good reason why the Soviet Union should now be asking whether its present arrangements for the management of industry are the only means by which the dictatorship of the proletariat can be exercised.

The plight of those exposed to fallout near Chernobyl but not acutely injured remains to be determined. Strictly speaking, it is a matter for the Soviet government, in its dealings with its own people, to decide. This week's statement says that those affected by the enormous disruption caused by the accident will be compensated, though it is not clear what that means. But there is a great need that there should be close medical surveillance of those affected for several decades to come. It is not merely that there is a great deal to learn about the effects of low-level radiation exposure. or that there are ethical considerations which require that those now at greater risk from cancer than most others should be given as timely a warning as possible, but that this is a chance for the Soviet Union to make good its previously poor record for compassion.

\section{Packing for the summit?}

There may be a Soviet-US summit this year if only a package of agreements can be found.

Optimism earlier this year that 1986 would be the year in which the first arms control agreement this decade would be signed seems to be strengthening again, against the odds, and in spite of the succession of disagreements between the two major powers that have studded the past few months. And while the latest developments amount to nothing more substantial than straws in the wind, they do suggest that the two sides will eventually talk to each other, at a summit meeting later in the year. That is something for which many people will be grateful. But the likely 